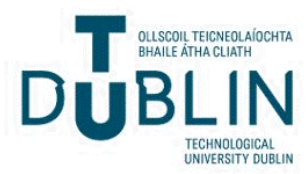

Technological University Dublin

ARROW@TU Dublin

\section{Folded Meander Line Antenna for Wireless M-Bus in the VHF and UHF Bands}

\author{
Abraham Loutridis \\ Technological University Dublin \\ Matthias John \\ Trinity College Dublin, matthias.john@tudublin.ie \\ Max Ammann \\ Technological University Dublin, max.ammann@tudublin.ie
}

Follow this and additional works at: https://arrow.tudublin.ie/ahfrcart

Part of the Systems and Communications Commons

\section{Recommended Citation}

A. Loutridis, M. John, and M. J. Ammann, (2015) Folded Meander Line Antenna for Wireless M-Bus in the VHF and UHF Bands. Electronics Letters, vol. 51, issue 15, pp. 1138 - 1140, 07/2015. doi:10.1049/ el.2015.1844

This Article is brought to you for free and open access by the Antenna \& High Frequency Research Centre at ARROW@TU Dublin. It has been accepted for inclusion in Articles by an authorized administrator of ARROW@TU

Dublin. For more information, please contact

arrow.admin@tudublin.ie, aisling.coyne@tudublin.ie, gerard.connolly@tudublin.ie.

Funder: SFI

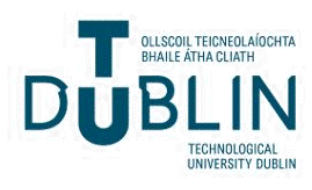




\section{Folded Meander Line Antenna for Wireless M-Bus in the VHF and UHF Bands}

\author{
A. Loutridis, M. John, and M.J. Ammann
}

The first dual-band printed monopole antenna for Wireless M-Bus and M2M applications with operation in the VHF and lower UHF band is presented. The antenna operates at $169 \mathrm{MHz}$ and $433 \mathrm{MHz}$. The miniaturisation of the proposed compact antenna is based on a doublesided meandering structure offering an easily controlled large frequency-ratio. The antenna is offering high total efficiency and gain in both bands. Measured and simulated results are reported.

Introduction: In recent years, intelligent metering systems for the measurement of water, gas, heat, and electricity consumption have attracted increased attention enabling competitive and efficient commercial solutions.

The Wireless M-Bus standard (EN13757-4:2013) [1] which defines the radio frequency link between a smart consumption meter and the data collecting device, is widely used in Advanced Metering Infrastructure (AMI) applications. Wireless M-Bus was originally designated to operate in the $868 \mathrm{MHz}$ band, allowing good propagation conditions with compact and efficient designs. The emphasis on the demand for harmonised frequency bands for several existing and new applications led the Electronic Communication Committee (ECC) [2] to reconsider the use of the $169 \mathrm{MHz}$ and $433 \mathrm{MHz}$ bands. The two new entrant bands which were added to the wM-Bus specification, introduce a narrow band channel $(75 \mathrm{kHz})$ with a maximum EIRP of $+27 \mathrm{dBm}$, providing longer range solutions than at $868 \mathrm{MHz}$.

In a smart metering grid, smart devices are generally located inside buildings, and communicate with data collectors which are positioned on the rooftop or on street lamps. Due to the poor indoor propagation conditions, limited available power and the increase in path loss with frequency, technologies above $1 \mathrm{GHz}$ are unsuitable. The choice of operating frequencies in the $169 \mathrm{MHz}$ and $433 \mathrm{MHz}$ bands is necessary to provide satisfactory indoor reception, overcoming the high building penetration losses, increasing battery lifetime and the power link budget.

The size of a typical metering device is around $150 \times 150 \mathrm{~mm}^{2}$. This space must house the electronic components, battery and the integrated antenna. The limited available antenna space intensifies the challenge of trading antenna dimensions for performance. A variety of different antenna types for smart metering devices are commercially available which operate only in $169 \mathrm{MHz}$. Normal mode helical monopoles [3] are common with an average size of $14.2 \mathrm{~mm} \times 160 \mathrm{~mm}$ (diameter $\times$ height) and a reported gain of $-1 \mathrm{dBi}$, but no ground plane specified. These monopole types are still too large and high profile for integration. Chip antennas [4] are compact sized $(25 \mathrm{~mm} \times 5 \mathrm{~mm} \times 0.8 \mathrm{~mm})$ and suitable to meet the limited space requirements, but the poor gain $(-17.6 \mathrm{dBi})$ makes them an unattractive solution. In the data sheet [5] a shorted helical monopole antenna for smart metering is proposed with dimensions of $44 \mathrm{~mm} \times 35 \mathrm{~mm}$ (diameter $\times$ height), a gain of $-8 \mathrm{dBi}$ and bandwidth of $8 \mathrm{MHz}$. The efficiency is not reported and the antenna is located on a ground plane of size $75 \mathrm{~mm} \times 75 \mathrm{~mm}$. In [6], a reconfigurable VHF helix antenna for handheld devices with size of $134 \mathrm{~mm} \times 64 \mathrm{~mm} \times 9.6 \mathrm{~mm}$ is reported. The simulated radiation efficiency is around $2.5 \%$ but no gain is specified. A dual-band VHF/UHF antenna for portable devices [7] with dimensions of $235 \mathrm{~mm} \times 68 \mathrm{~mm} \times 10.8 \mathrm{~mm}$ is presented, providing simulated realized gain less than $-12 \mathrm{dBi}$ and no reported efficiency. Moreover, in [8] an inverted-L folded antenna for mobile handsets is proposed with dimensions of $148 \mathrm{~mm} \times 49 \mathrm{~mm} \times 11 \mathrm{~mm}$. The measured gain of the antenna is around $-8 \mathrm{dBi}$, efficiency is not available. The antenna is located a ground plane of $200 \mathrm{~mm} \times 100 \mathrm{~mm} \times 1.6 \mathrm{~mm}$.

In this paper, the first dual-band antenna for Wireless M-Bus and M2M applications operating at $169 \mathrm{MHz}$ and $433 \mathrm{MHz}$ is presented. The printed antenna is low-profile, compact and suitable for integration. It provides omnidirectional radiation characteristics and excellent measured total efficiency of $20.4 \%$ and $49.4 \%$ at $169 \mathrm{MHz}$ and
$433 \mathrm{MHz}$, respectively. This high efficiency is essential for the proposed applications and marks a considerable improvement over the state of the art.

Antenna Configuration: The antenna (Fig. 1) is printed on double-sided FR4 substrate, $\left(\varepsilon_{\mathrm{r}}=4.4, \tan \delta=0.025\right)$ with metallization thickness of $0.035 \mathrm{~mm}$ and dimension of $150 \mathrm{~mm} \times 150 \mathrm{~mm} \approx\left(0.085 \lambda_{0}\right.$ at $\left.169 \mathrm{MHz}\right)$ representing the meter motherboard. The meandered monopole of height $h=40.23 \mathrm{~mm}\left(\approx 0.02 \lambda_{0}\right)$ and length $l=45.02 \mathrm{~mm}\left(0.025 \lambda_{0}\right)$ is located on the corner of the ground plane. The antenna is fed with an SMA connector through a $50 \Omega$ microstrip line (width $=2.94 \mathrm{~mm}$ ) which is stepped to a short section (length $=0.85 \mathrm{~mm}$ and width $=0.35 \mathrm{~mm}$ ) which connects to the antenna through via 1 . The rear meander line (width $=0.35 \mathrm{~mm}$ ) with uniform spacing runs up the substrate to via 2 which connects to an extended meander line section located at the front with an $4.52 \mathrm{~mm}$ open end which terminates at the ground plane level. The rear meandered section determinates the upper resonance and the combined line sections provide the lower resonance. The frequency ratio $f_{2} / f_{1}$ of 2.56 is tuned/optimized by non-uniformity in the front meander line section as well as some coupling of the front and back meander lines. Placing meander line sections on opposite sides of the PCB provides isolation, miniaturization and greater freedom in controlling the frequency ratio.

The introduction of a shunt lumped inductor $(L=56 \mathrm{nH}, 0.2 \Omega)$ $20.15 \mathrm{~mm}$ away from Via 1 improves the matching at both frequencies as shown in Fig 2.

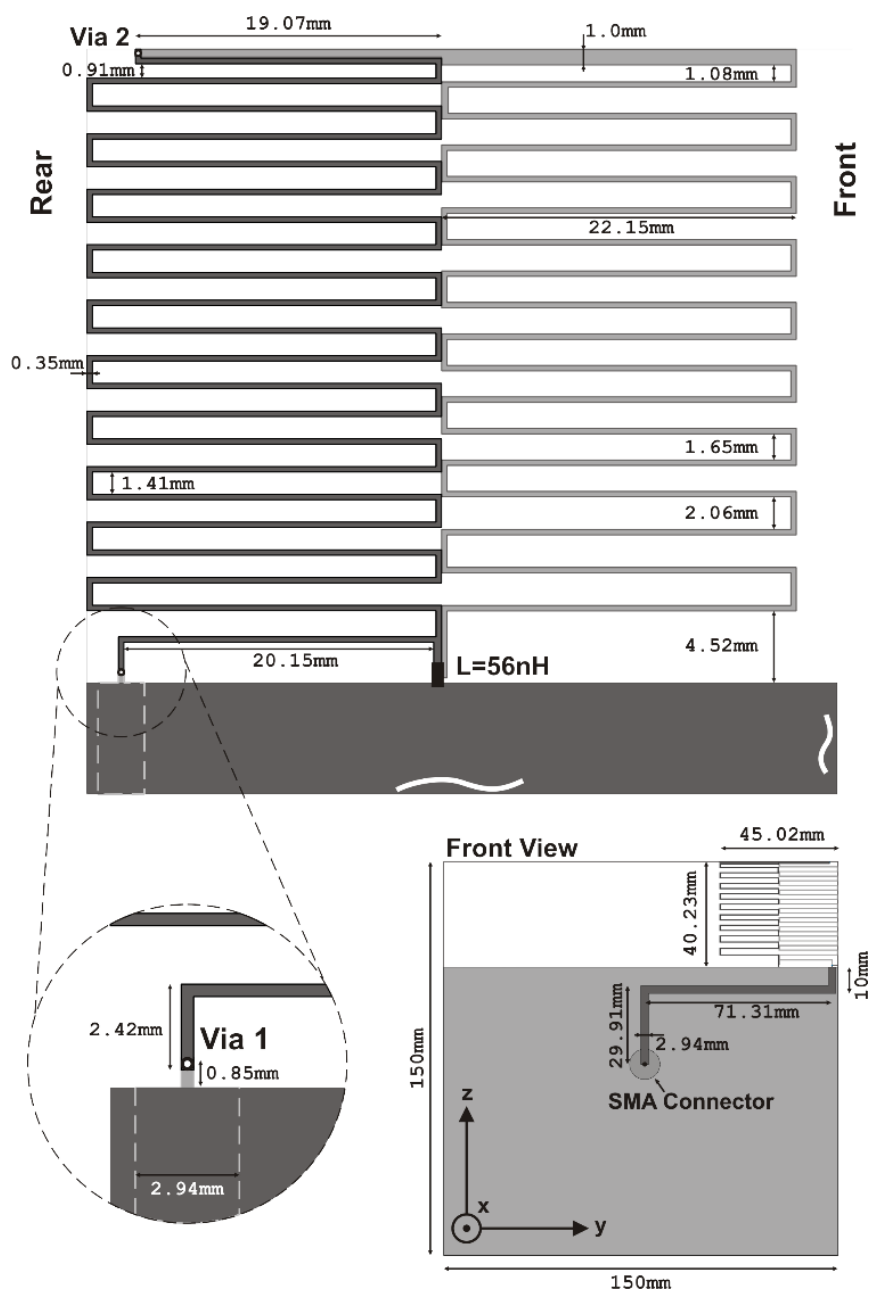

Fig. 1 Folded meander line monopole antenna.

Results and Discussion: Fig. 3 shows the measured and simulated $\mathrm{S}_{11}$ to be in good agreement. The measured $-6 \mathrm{~dB}$ and $-10 \mathrm{~dB}$ impedance bandwidth was $5.8 \mathrm{MHz}(165.7-171.5 \mathrm{MHz})$ and $3.3 \mathrm{MHz}$ (167$170.3 \mathrm{MHz})$ respectively at $169 \mathrm{MHz}$, and $53.9 \mathrm{MHz}$ (417.5471.4 MHz) and 26.4 MHz (424.7-451.1 MHz) at $433 \mathrm{MHz}$. 


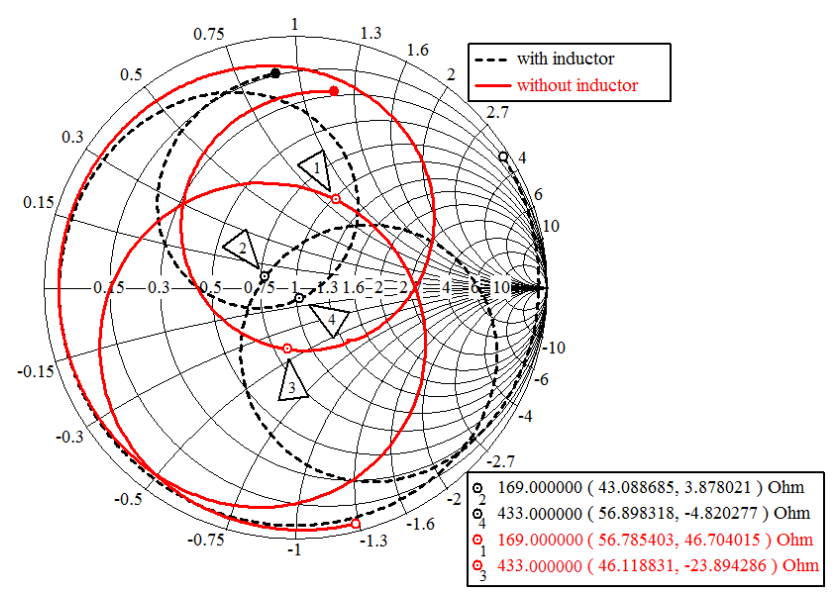

Fig. 2 Smith chart showing matching component effect.

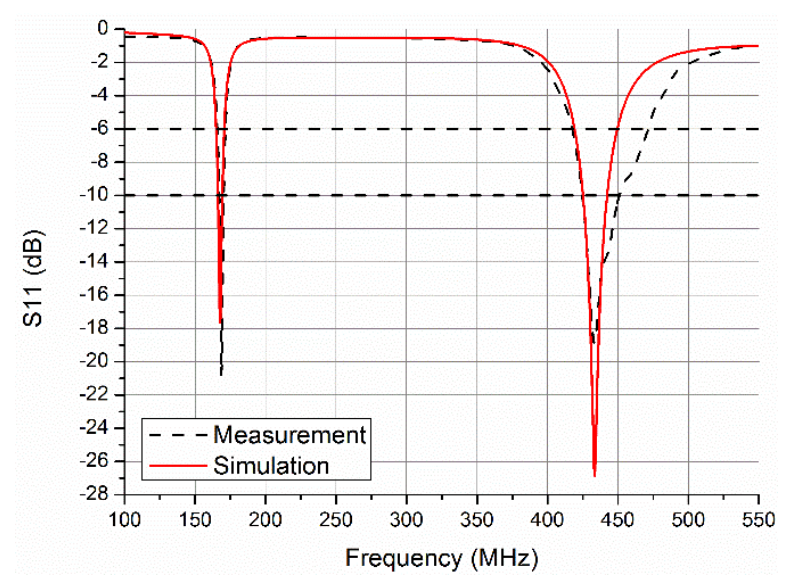

Fig. 3 Simulated and measured $S_{11}$.

Simulations of the radiation and total efficiency were made for $169 \mathrm{MHz}$ and $433 \mathrm{MHz}$ using CST Microwave Studio. Measurements were performed using the Wheeler cap method using a metallic box of $610 \times 610 \times 360 \mathrm{~mm}^{3}$.

The measured radiation and total efficiency for the first resonance is $20.4 \%$. For the second resonance the measured radiation and total efficiency is $50 \%$ and $49.4 \%$ respectively. These results are in good agreement with simulation which indicate a radiation and total efficiency of $18.3 \%$ and $17.8 \%$ at $169 \mathrm{MHz}$ and $48.2 \%$ and $47.9 \%$ at $433 \mathrm{MHz}$ respectively.

In Figs. 4 and 5 the measured and simulated azimuth (x-y) and elevation $(\mathrm{x}-\mathrm{z})$ plane radiation patterns at $433 \mathrm{MHz}$ are illustrated. The maximum measured gain is $4.6 \mathrm{dBi}$. There is a good agreement between measurement and simulation. The maximum simulated realized gain at $169 \mathrm{MHz}$ is $-1.8 \mathrm{dBi}$. There are no facilities available to us to provide measured radiation patterns at $169 \mathrm{MHz}$.

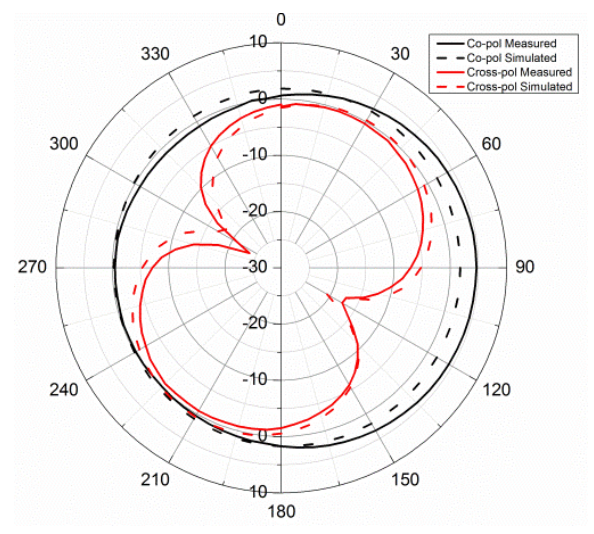

Fig. 4 Azimuth radiation patterns in the xy-plane at $433 \mathrm{MHz}$.

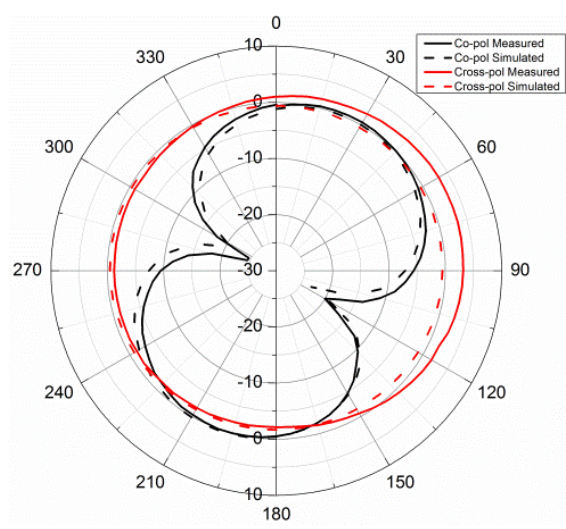

Fig. 5 Elevation radiation patterns in the xz-plane at $433 \mathrm{MHz}$

Conclusion: A dual band folded meander line monopole antenna for emerging smart metering applications at 169 and $433 \mathrm{MHz}$ is presented. The proposed antenna is compact with omnidirectional radiation characteristics providing more than $20 \%$ and $49 \%$ measured total efficiency at $169 \mathrm{MHz}$ and $433 \mathrm{MHz}$ respectively. The measured gain at $433 \mathrm{MHz}$ is $4.6 \mathrm{dBi}$ and the simulated gain at $169 \mathrm{MHz}$ is $-1.8 \mathrm{dBi}$. The antenna is low cost and easy fabricated with additional benefit of a large frequency ratio range which is easy to control.

Acknowledgments: This material is based upon works supported by the Science Foundation Ireland under Grant No. 10/CE/I1853.

A. Loutridis and M. J. Ammann (Antennas and High Frequency Research Centre, School of Electrical \& Electronic Engineering, Dublin Institute of Technology, Kevin St., Dublin 8, Ireland)

E-mail: abraham.loutridis@mydit.ie

M. John (CTVR, Trinity College Dublin, Dublin 2, Ireland)

\section{References}

1. European Committee for Standardization, "EN 13757-4," 2013.

2. Electronic Communication Committee (ECC) Decision (05)02, "A harmonised frequency plan for the use of the band 169.4-169.8125 MHz," Amended 8 November 2013.

3. Portable Helical $169 \mathrm{MHz}$ ISM Antenna, Panorama Antennas, http://www.panorama-antennas.com/datasheets/catalogues/m2m.pdf

4. 2JE06-Embedded/SMT $169 \mathrm{MHz}$ Chip Antenna, http://www.2jantennae.com/images/products/2JE06.PDF

5. TAS 169-Transiver Antenna System, Hirschmann Solutions, http://hirschmannsolutions.com/fileadmin/downloads/Datasheets/TAS_ 169_D_Datenblatt.pdf

6. T.-W. Lien, C.-F. Yang, T.-G. Ma, C.-H. Wu, Y.-L. Chien and W.-S. Chen, "A Reconfigurable VHF Antenna to be Embedded in a Handheld Device for an Emergency System," IEEE Antenna and Propagation Society International Symposium (APSURSI), 2014, pp. 1248-1249.

7. A.R. Weily, K.W. Smart and T.S. Bird, "Dual-band VHF/UHF smartphone antenna for mobile digital television," International Workshop on Antenna Technology (iWAT), 2014, pp. 228-231.

8. W. Kim, S. Jeon and J. Choi, "Internal Dual-band Low Profile Antenna for T-DMB/UHF Mobile Handset Applications," IEEE Antennas and Propagation Society International Symposium (APSURSI), 2006, pp. 4265-4268. 